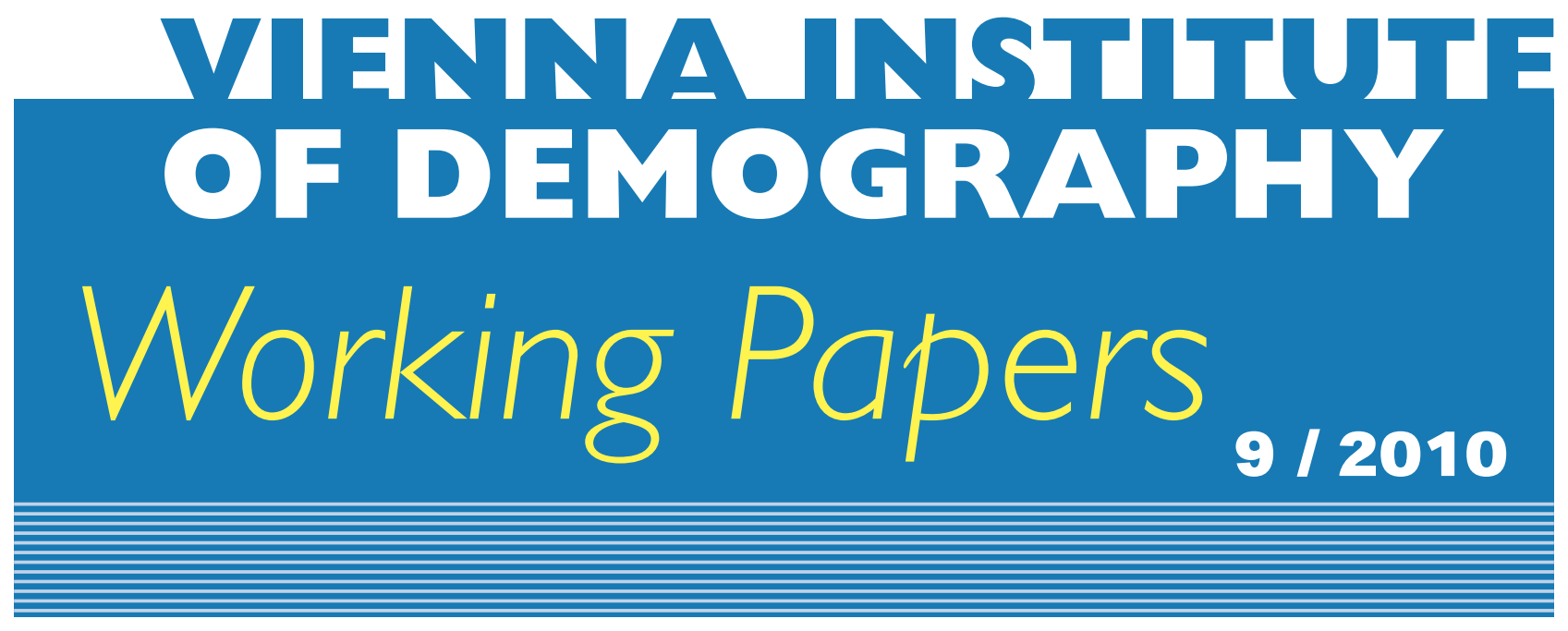

Holger Strulik, Klaus Prettner, and Alexia Prskawetz

\title{
R\&D-Based Growth in the Post-Modern Era
}

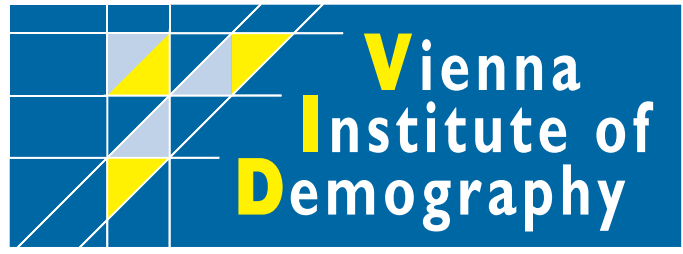

Vienna Institute of Demography Austrian Academy of Sciences

Wohllebengasse 12-14

A-I040Vienna $\cdot$ Austria

E-Mail:vid@oeaw.ac.at

Website: www.oeaw.ac.at/vid 


\begin{abstract}
Conventional R\&D-based growth theory suggests that productivity growth is positively correlated with population size or population growth, an implication which is hard to see in the data. Here we integrate micro-founded fertility and schooling into an otherwise standard R\&D-based growth model. We then show how a Beckerian child quality-quantity trade-off explains why higher growth of productivity and income per capita are associated with lower population growth. The medium-run prospects for future economic growth - when fertility is going to be below replacement level in virtually all fully developed countries - are thus much better than predicted by conventional R\&D-based growth theory.
\end{abstract}

JEL classification: J13, J24, O10, O30, O40

\title{
Keywords
}

Endogenous growth, R\&D, declining population, fertility, schooling, human capital, postmodern society, post-transitional fertility.

\section{Authors}

Holger Strulik, School of Economics and Management, University of Hannover, Germany; email: strulik@vwl.uni-hannover.de

Klaus Prettner, Vienna Institute of Demography, Austrian Academy of Sciences, and Institute of Mathematical Methods in Economics, Vienna University of Technology; email:

klaus.prettner@,oeaw.ac.at

Alexia Prskawetz, Institute of Mathematical Methods in Economics (research group on economics), Vienna University of Technology, and Vienna Institute of Demography, Austrian Academy of Sciences; email: afp@econ.tuwien.ac.at

\section{Acknowledgements}

We would like to thank Carl-Johan Dalgaard, Oded Galor, and Peter Howitt for helpful comments. 


\title{
R\&D-based Growth in the Post-modern Era
}

\author{
Holger Strulik, Klaus Prettner, Alexia Prskawetz
}

\section{INTRODUCTION}

A characteristic feature of economic theories designed to explain the performance of human societies over the very long run is that they are emphasizing the interaction between economic and demographic variables as crucial for our understanding of economic development (see Galor, 2005, 2010 for surveys). Broadly speaking, these "unified growth theories" explain why the demoeconomic history of countries or regions can be conceptualized as subdivided into two periods: the Malthusian era and the modern era. During the Malthusian era fertility and mortality are high, the population is constant or slowly expanding fuelled by (relatively small) productivity gains, and income stagnates at a low level. During the modern era fertility and mortality are both low and productivity gains translate into perpetual economic growth at high and (ideally) constant rates. Both eras are connected by a demographic transition during which mortality and fertility decline, the population growth rate first rises and then declines, and the economy takes off.

This paper introduces a third era to the analysis of long-run growth, the post-modern era. The characteristic feature of the post-modern era is a secular trend of declining population. So far, the consequences of a declining population have been relatively little researched in the field of long-run economic growth. Many theories were based on the assumption of a constant population. This assumption was until recently in line with many demographic projections, which predicted that the demographic transition comes to its end when fertility rates approach replacement level. For example, past population projections of the United Nations and the World Bank assumed in their medium variants (which were regarded as most likely) that fertility rates everywhere converge towards 2.1 births per women (Bongaarts, 1999).

Actually, however, the idea that the demographic transition stops at replacement level is refuted by empirical evidence. The total fertility rate (TFR) fell below replacement level in the 1970s in Europe and Japan, in the 1980s in North America and Australia, and in the 1990s in the Asian Tiger countries (Bongaarts, 2001). It is now below replacement level in all 50 European countries but Turkey and in 80 countries in the world (UN, 2007). Table 1, compiled from UN (2007), shows the most recently observed TFR for the G-8 countries, i.e. those countries that 
we usually associate with production at the "frontier of technological knowledge" (Aghion and Howitt, 2009). In every country that contributes substantially to innovation-based, R\&D-driven growth the TFR is below replacement level.

\begin{tabular}{cclc} 
TABle 1: & TFR FOR THE G-8: 2005 \\
\hline \hline USA & 2.05 & France & 1.89 \\
U.K. & 1.82 & Canada & 1.53 \\
Italy & 1.38 & Germany & 1.36 \\
Russia & 1.34 & Japan & 1.24 \\
\hline \hline
\end{tabular}

Among the developed countries the U.S. is unique in displaying a TFR close to replacement level. Table 2, compiled from U.S. National Center for Health Statistics (2010), shows that this achievement originates solely from the high TFR of the Hispanic part of the population. The TFR of non-Hispanic whites (1.83), for example, is close to that of their European forefathers. Assuming that fertility behaviour of immigrants is at least partly rooted in the fertility norms of their country of origin we expect fertility of the Hispanic population in the U.S. to fall below replacement level with ongoing fertility transition in the countries of origin. Some Latin American countries (e.g. Chile, Brazil, Cuba) display already fertility below replacement and for other countries this seems to be likely in the future. In face of the observable trends, the United Nations have recently updated their medium-variant projection, now assuming that all countries in the world converge towards a TFR of 1.85 in the long run, i.e. a fertility pronouncedly below replacement level (UN, 2007).

\begin{tabular}{ll} 
TABLE 2: TFR USA 2008 \\
\hline \hline Non-Hispanic white & 1.83 \\
Asian-American & 2.05 \\
Black & 2.11 \\
Hispanic & 2.90 \\
\hline \hline
\end{tabular}

There is evidence, however, that the UN assumption of fertility rates converging towards 1.85 could be too optimistic. Strulik and Vollmer (2010) show that the countries of the world can be subdivided into two fertility groups: in one group fertility rates are converging, in the other group fertility rates are not converging, indicating that the fertility transition is not yet initiated or yet too slow for catching up with the forerunners of the transition. For the convergence-group Strulik and Vollmer show a strong linear correlation of initial fertility in $1950\left(F_{50}\right)$ and fertility reduction 1950-2005 $(\Delta F)$ with no indication of levelling off at low fertility rates. The prediction 
implied by the estimated $\beta$-convergence equation $\Delta F=0.82-0.73 F_{50}$ is a steady-state (longrun equilibrium) at a TFR of $0.82 / 0.73=1.12$, i.e. somewhat more than one child per women, almost about half of replacement fertility.

The observation that fertility is below replacement in virtually every developed country has motivated demographers to speak of "post-transitional" societies (e.g. Bongaarts, 2001). This categorization, however, could be misleading. It could be interpreted as indicating that the fertility transition has been accomplished. As shown above, this is not yet the case. Fertility rates continue to fall, although - according to $\beta$ convergence - at subsequently lower rates. It may thus be more appropriate to follow van der Kaa (2001) and speak of post-modern societies. ${ }^{1}$

While post-modernity is a complex idea and post-modern values and their emphasis of private life and material goods (instrumental post-modernism) or the public world and social goods (humanist post-modernism) may affect virtually every aspect of life, we focus here on one aspect: the demand for children. The post-modern society is characterized by values and norms such that couples on average give birth to fewer than two children (van de Kaa, 2001, Caldwell and Schindlmayer, 2003, Preston and Hartnett, 2008). Subsequently we take preferences as given and ask for the consequences on economic growth.

According to conventional theories of R\&D-based growth, the fact that the population is declining entails a grim economic outlook for post-modern societies. Models of the first generation (Romer, 1990, Aghion and Howitt, 1992) provide the result that growth of aggregate productivity (TFP) is linearly related to population size. Thus, a declining population implies vanishing growth of productivity and income per capita. According to models of the second generation (Jones, 1995, Kortum, 1997, Segerstrom, 1998), TFP growth is linearly related to population growth. If we would rule out declining productivity, these models would predict for the post-modern era stagnation of productivity and income per capita. ${ }^{2}$

Fortunately, the empirical evidence does not support these predictions. Many studies have demonstrated a negative association between population growth and income growth (e.g. Brander and Dowrik, 1994, Kelley and Schmidt, 1995, Ahituv, 2001, and Herzer et al., 2010). Also

\footnotetext{
${ }_{1}$ In the very long run it is probably also hard to imagine that world population declines forever, i.e. until extinction. At some point we may expect that economic mechanism increase the rewards for children strongly enough to initiate a turn of the fertility transition towards convergence to replacement level from below.

${ }^{2} \mathrm{R} \& \mathrm{D}$ Models of the third generation (Peretto (1998), Young (1998) and Howitt (1999) combine features of the earlier generations by investigating quality $R \& D$ and variety $R \& D$. Assuming that there exist no knowledge spillovers between quality and variety $R \& D$ they predict that only variety growth is essentially associated with population growth while constant quality growth requires a constant population. See Jones (1999) for a survey and $\mathrm{Li}$ (2000) for a critique and further generalization.
} 
the positive association between population growth and productivity growth predicted by conventional R\&D-based growth theory is hard to see in the data. Because knowledge spillovers decline with distance and are smaller across countries than within countries (Jaffe et al., 1993, Keller, 2002, Bottazzi and Peri, 2003), we would expect that at least some of the high TFP growth generated in countries where population growth is high to be visible in the data. Figure 1 shows average annual population growth against average annual TFP growth from 1960 to 1998 (as calculated in Weil, 2005). Across all countries for which data is available (identified in the Figure by blue crosses) the simple correlation is clearly negative; the estimated slope of the regression by OLS is $-0.17\left(R^{2}=0.18\right)$, see Bernanke and Guerkaynak (2001) for a similar finding.

Figure 1: Population Growth vs. TFP Growth 1960 -1998

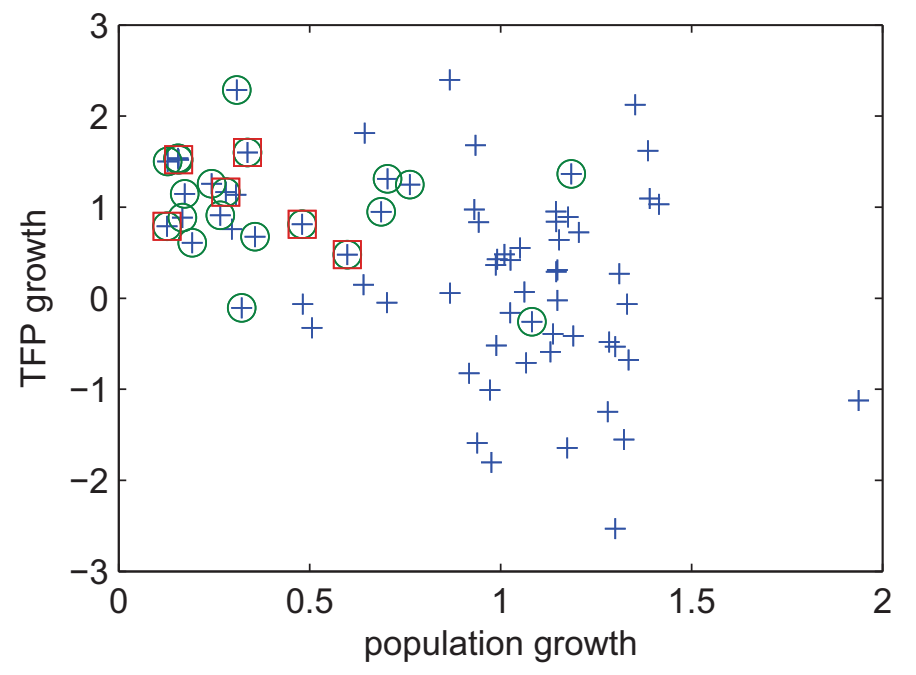

Growth rates are average annual growth rates 1960-1998 in percent as compiled in Weil (2005). Blue crosses: all available countries, green circles: OECD countries, red squares: G7 countries.

For a proper check of R\&D-based growth theory, however, it seems reasonable to reduce the sample, acknowledging the fact that less developed countries - where usually population growth is highest - do not much advance TFP growth by market R\&D activities. But if we focus just on OECD countries (green circles in the Figure) the predicted positive association is still not visible (the estimated slope of the regression line is $-0.13, R^{2}=0.06$ ). Even if we assume that conventional R\&D-based growth theory applies foremost to the G7 countries, i.e. a small group of countries that pushes the world technology frontier (identified in the Figure by red squares), 
the predicted positive association remains invisible (the "estimated" slope of the regression line is $\left.-0.22, R^{2}=0.29\right)$.

Shifting the focus towards population levels and a historical perspective of technology evolution over the very long-run, Comin et al. (2010) have recently shown that across countries the present level of technology is positively associated with the level of technology in the year 1500 and negatively associated with population size in 1500. Interestingly they have also shown a positive association of population size in year $0 \mathrm{AD}$ with the level of technology in 1500 . Thus the population push view that a larger population produces more ideas (see also Kremer, 1993, Strulik and Weisdorf, 2008) seems to be true in the ancient and medieval past but not for modern societies. The present paper offers an explanation for this phenomenon by arguing that the reversal occurred when a child-quantity substitution became operative and parents began to invest in education of their children.

Below we will refine the view on the human factor in TFP growth and argue that it is not the sheer number of workers $(L)$ that propels the creation of ideas and the advancement of productivity but the total amount of knowledge embodied in these workers, i.e. aggregate human capital $(H)$. The most intuitive aggregation is probably that aggregate human capital is given by human capital per worker $h$ times the number of workers $(H=h \cdot L)$. Utilizing this notion of human capital and endogenizing the incentive to acquire it through costly schooling, a couple of papers have demonstrated that human capital growth can take over the role of population growth in R\&D-based growth models by predicting that productivity growth can be sustained with constant or declining population as long as human capital is accumulated rapidly enough. This prediction is less easily refuted by the data since empirical evidence supports a positive association between proxies of human capital accumulation and growth of income per capita and TFP. ${ }^{3}$

While the integration of human capital accumulation into R\&D-based growth theory provides a way around the need for constant population size or a positive rate of population growth in order to sustain long-run economic growth, the so far available literature has left unsolved the problem of the potentially negative association of population growth and TFP growth. To be

${ }^{3}$ For theory see, among others, Arnold (1998), Funke and Strulik (2000), Dalgaard and Kreiner (2001), Strulik (2005), Dalgaard and Jensen (2009), Grossmann (2010). For evidence see Bernanke and Guerkaynak (2001), Barro (2001), Krueger and Lindahl (2001). Authors of the original R\&D-based growth model sometimes acknowledge the fact that it is $H$ rather than $L$ that drives the development of new ideas, see e.g. Romer (1990). However, this observation has not motivated them to integrate an explanation of the accumulation of $H$ into the model. 
specific, acknowledging that aggregate human capital, $H=h \cdot L$, matters for the creation of new ideas, the fundamental problem is to explain why productivity growth seems to be positively associated with increasing $h$ and negatively associated with increasing $L$. This problem remained unsolved because the available literature has neglected the interaction of quantity and the quality of the workforce.

Indeed, there exists no obvious way to explain at the macro-level how $L$ and $h$ could potentially contribute conversely to the aggregate $h \cdot L$. On the micro-level, however, there exists a wellestablished and tested theory precisely for this, the Beckerian child quantity-quality trade-off (Becker, 1960, Rosenzweig, Wolpin, 1980, Rosenzweig, 1990, Hanushek, 1992). This mechanism, which plays also a crucial role in unified growth theory (Galor, 2005), allows parents to substitute child quality for child quantity such that $h$ rises and $L$ falls. If the substitution is such that $h$ rises more strongly than $L$ falls, the micro-foundation can motivate that aggregate human capital $H$ in a society rises although the population declines. If, in turn, the development of ideas and thus TFP growth is driven by $H$, the micro-foundation explains why we observe a negative association between TFP growth and population growth at the macro-level.

Utilizing these ideas, the present paper integrates for the first time a micro-founded child quantity-quality trade-off into R\&D-based growth theory and shows why and how a change of preferences towards less children can provide the result of increasing aggregate human capital. This way, R\&D-based growth theory is accommodated to the evidence on education, fertility and TFP growth. At the same time the "old" theory is not completely abandoned. It is still there when the corner solution for education applies. If preferences do not support a quantity-quality substitution, increasing fertility and population growth contribute positively to economic growth as evidenced for most of human history. On the other hand, if the quantityquality trade-off is operative, the direction of the aggregate effect is independent from family size and, in particular, also observed for fertility below replacement level. Taken together these results identify child quantity-quality substitution as the causal driver of R\&D-based growth for post-modern societies. ${ }^{4}$

The paper is organized as follows. The next section sets up the model. Section 3 analyses the balanced growth path and proves our main results. Section 4 investigates the corner solution and

\footnotetext{
${ }^{4}$ So far, a few scientific articles have integrated endogenous fertility into R\&D-based growth, notably Jones (2001), Connolly and Peretto (2003) and Growiec (2006). Articles integrating education have been referenced above. To our best knowledge, an integration of the simultaneous fertility-education decision, the crucial element that establishes growth for the post-modern society, does not yet exist.
} 
how the new theory relates to the existing literature. Section 5 specifies the model numerically, investigates adjustment dynamics and compares economic growth in the modern era and the post-modern era. The final section concludes with a tentative outlook for future economic development.

\section{The Model}

2.1. Households. Consider an economy populated by three overlapping generations, children, young adults, and old adults. Children consume the provisions received by their parents and (possibly) experience an increase of their human capital endowment through education. Old adults consume their savings plus interest. Young adults supply one unit of labour and decide how to split their income between current consumption and future consumption, how many children they want to have, and how much they want to spend on their children's education.

In order to convey the basic theory conveniently and to get explicit solutions, we make a number of simplifying assumptions. Each household consists of one parent (which avoids to tackle matching problems), there is no mortality in childhood and young adulthood (which avoids problems of uncertain survival), children are a continuous number (which avoids problems of indivisibility), and the motive of child expenditure is non-operational (which avoids problems of maximizing dynastic value functions). This means that parents' motivation to spend on children's education is not driven by the anticipation of the increase of children's utility caused by this expenditure but by a "warm glow" of giving (Andreoni, 1989) or the desire for having "higher quality" children (Becker, 1960).

To be specific let $c_{t}^{1}$ and $c_{t}^{2}$ denote consumption of the young and old in period $t$. The currently young, facing a gross interest rate $R_{t+1}$, and making a savings decision $s_{t}$, expect future consumption $c_{t+1}^{2}=R_{t+1} s_{t}$. A young adult's human capital is denoted by $h_{t}$ and the wage per unit of human capital is denoted by $w_{t}$. Let $n_{t}$ denote the number of children and $\tau$ the time cost involved in having a child. Besides these necessary costs, parents may voluntarily spend $e_{t}$ per child, conceptualized in the Beckerian sense as child quality expenditure. Plugged into a function for education, quality expenditure determines the human capital endowment of next period's generation $\left(h_{t+1}\right)$. Since the parameters of education and futures wages are given to the single adult, having expenditure $e_{t}$ or next period's endowments $h_{t+1}$, or wage income of their children $w_{t+1} h_{t+1}$ in the utility function leads to equivalent results. Summarizing, young 
adults solve the problem

$$
\max _{c_{t}, s_{t}, e_{t}, n_{t}} u_{t}=\log c_{t}^{1}+\beta \log \left(R_{t+1} s_{t}\right)+\gamma \log e_{t}+\eta \log n_{t}
$$

subject to the budget constraint $w_{t} h_{t}\left(1-\tau n_{t}\right)=c_{t}^{1}+s_{t}+n_{t} e_{t}$. The positive parameters $\beta, \gamma$, and $\eta$ denote the weights of future consumption, child expenditure, and family size for utility, i.e. the importance of these elements relative to current consumption.

The solution of the decision problem for current consumption is $c_{t}=w_{t} h_{t} /(1+\beta+\eta)$ and the solutions for savings, child expenditure, and fertility are

$$
\begin{aligned}
s_{t} & =\frac{\beta w_{t} h_{t}}{1+\beta+\eta}, \\
e_{t} & =\frac{\gamma \tau w_{t} h_{t}}{\eta-\gamma}, \\
n_{t} & =\frac{\eta-\gamma}{(1+\beta+\eta) \tau} .
\end{aligned}
$$

We assume $\eta>\gamma$ so that the problem has indeed a positive interior solution. Inspect the solution to verify that a decrease of $\eta$, i.e. of the importance of family size for utility, implies lower fertility and higher expenditure per child. The same results (with respect to direction not with respect to the strength of the effect) are observed for an increase of the importance of child expenditure $\gamma$ and an increase of the time costs of children $\tau$. The quantity-quality trade-offs initiated by these parametric changes will be at the center of the study of comparative statics of the balanced growth path later on. In particular we associate with a post-modern society in line with the arguments developed in the Introduction - a sufficiently low weight on family size $\gamma$ such that a couple of adults has less than 2.1 children $\left(n_{t}<1.05\right)$.

2.2. Education. Child expenditure $e_{t}$ is transformed into human capital of the next generation of young adults via a schooling technology. A reasonable technology does not just translate expenditure one to one into human capital but controls also for the costs of schooling. These costs can be conveniently approximated by the wage $w_{t}$, i.e. the cost of a unit of human capital of the current adult (teacher-) generation. The simplest conceivable schooling technology is given by

$$
h_{t+1}=\max \left\{A_{E} \frac{e_{t}}{w_{t}}, 1\right\}
$$


where $A_{E}$ signifies general productivity of schooling. If education expenditure is too small or productivity of schooling is too low, the next generation will have the same human capital endowment as the current generation and as the generations before. This constant level of skills is normalized to unity. ${ }^{5}$

Inserting (2) into the schooling technology provides a simple equation of motion for human capital:

$$
h_{t+1}=\max \left\{A_{E} \frac{\gamma \tau}{\eta-\gamma} h_{t}, 1\right\} .
$$

For the subsequent investigation we focus on an interior solution, i.e. the case where there is actually growth of human capital. Later on we return to the corner solution of constant human capital. ${ }^{6}$

2.3. Firms: Overview. The set-up of firms and markets follows closely Romer (1990) and Jones (1995). The economy consists of three sectors: The R\&D-sector is perfectly competitive and employs scientists to create new ideas in the form of blueprints, manifested in patents. A patent is needed as fixed input in a monopolistically competitive sector to produce a specialized capital good. Purchase of a patent allows a capital goods producer to transform one unit of raw capital, i.e. one unit of individual's savings, into one blueprint-specific machine. A perfectly competitive final goods sector uses these machines and workers to assemble a consumption aggregate.

Aside from the set-up in discrete time the "only" modification of the firm's side of the RomerJones model is that the human factor in production is human capital $H_{t}=h_{t} L_{t}$ where $L_{t}$ is the size of the current generation of young adults. Note that this aggregation of individual human capital $h_{t}$ implies an infinite elasticity of substitution between human capital per person and persons. It means that any lack of human capital that a firm's currently employed workers may display can be taken care of by just employing more workers of the same skill level.

2.4. Final goods sector. Since the firms' side of the model - aside from the special role of human capital - coincides with the Romer-Jones set-up, description can be brief. The final

\footnotetext{
${ }^{5}$ Whereas some elements of the schooling function could be made more general, controlling for the teachergeneration's wage is essential for dynamic stability. Otherwise human capital would grow hyper-exponentially, driven by increasing $h_{t}$ and rising $w_{t}$. A similar control for the current state of quality is known to be essential for stability in R\&D-driven quality improvements of products, see e.g. Li (2000).

${ }^{6}$ The assumption that human capital creation is a linear function of the expenditure share of education has provided a linear difference equation for human capital accumulation across generations. This linearity makes perpetual long-run growth possible. If there are decreasing returns there will be no (exponential) growth in the long-run. We discuss this possibility in the Conclusion.
} 
goods sector operates a Cobb-Douglas production technology

$$
Y_{t}=\left(H_{t}^{Y}\right)^{1-\alpha} \sum_{i=1}^{A_{t}} x_{i, t}^{\alpha}
$$

where $Y_{t}$ is output and $H_{t}^{Y}$ is employment. The parameter $\alpha$ is the capital share in final goods production, $x_{i, t}$ is the amount of a certain machine $i$ used in final goods production and $A_{t}$ is the state of technology, i.e. the number of available differentiated inputs. Facing a wage $w_{t}$ per unit of human capital, and rental prices $p_{i, t}$ for capital inputs $i=1, \ldots, A$, the indirect demand functions are given by

$$
\begin{aligned}
w_{t} & =(1-\alpha)\left(H_{t}^{Y}\right)^{-\alpha} \sum_{i=1}^{A_{t}} x_{i, t}^{\alpha}=(1-\alpha) \frac{Y_{t}}{H_{t}^{Y}} \\
p_{i, t} & =\alpha\left(H_{t}^{Y}\right)^{1-\alpha}\left(x_{i, t}\right)^{\alpha-1} .
\end{aligned}
$$

2.5. Capital Goods Production. Producers of specialized inputs transform one unit of raw capital into one unit of specialized capital such that $k_{t}=x_{t}$. Operating profits of an intermediate goods producer $\pi_{i, t}$ are thus given by $\pi_{i, t}=p_{i, t}\left(x_{i, t}\right) k_{i, t}-r_{t} k_{i, t}=\alpha\left(H_{t}^{Y}\right)^{1-\alpha}\left(k_{i, t}\right)^{\alpha}-r_{t} k_{i, t}$ where $r_{t}$ denotes the interest rate that has to be paid for individual's savings. Solving the associated problem of profit maximization facing demand (7) leads to the price of $p_{i, t}=p_{t}=r_{t} / \alpha$ for all $i=1, \ldots, A$ types of machines so that the machine-specific index can be dropped.

Free entry into capital goods production implies that in equilibrium operating profits are covering the fixed costs of production originating from purchasing a patent. In slight deviation from the original set-up and inspired by Aghion and Howitt (2009, Chapter 4) we assume that a patent holds for one period (i.e. one generation) and that afterwards the monopoly right to produce a good passes to someone chosen at random from the next generation. This simplification helps to avoid intertemporal (dynastic) problems of patent holding and patent pricing while keeping the basic incentive to create new knowledge intact. Summarizing, free entry implies $\pi_{i, t}=\pi_{t}=p_{t}^{A}$ where $p_{t}^{A}$ is the price of a patent (blueprint).

Because capital goods are sold at the same price and demanded at equal quantities, $x_{i, t}=x_{t}$, they can easily be added up to the aggregate capital stock $K_{t}=A_{t} x_{t}$. Inserting this information into the production of final goods, equation (5) simplifies to

$$
Y_{t}=A_{t}^{1-\alpha}\left(H_{t}^{Y}\right)^{1-\alpha} K_{t}^{\alpha}
$$


On the aggregate the number of developed specialized inputs appears as aggregate productivity in goods production and, following the literature, we will associate growth of $A$ with growth of aggregate factor productivity (TFP).

2.6. R\&D. Between periods $t$ and $t+1$ competitive R\&D-firms employ $H_{t}^{A}$ researchers to develop $A_{t+1}-A_{t}$ new blueprints and sell them at price $p_{t}^{A}$. Facing research productivity $\delta$ output is given by

$$
A_{t+1}-A_{t}=\delta H_{t}^{A}
$$

Research productivity $\delta$ is given to the single firm but depends, on the aggregate level, positively on the number of already existing ideas $(0<\phi<1$, standing-on-shoulders effect) and possibly negatively on the number of researchers ( $0 \leq \nu<1$, stepping-on-toes), $\delta=\bar{\delta} A^{\phi} L^{-\nu}$, where $\bar{\delta}>0$ is a scaling parameter. Note that the negative stepping-on-toes effect increases in the number of researchers $L_{t}$, not in aggregate human capital $H_{t}$. The reason is that there cannot be stepping-on-toes with respect to $h_{t}$ because the same researcher will not be paid to develop the same idea twice. Two researchers, in contrast, may indeed independently develop the same idea twice, in particular if they are employed by different R\&D firms.

Maximization of profits $p_{t}^{A} \delta H_{t}^{A}-w_{t} H_{t}^{A}$ leads to labour demand such that $w_{t}=\delta p_{t}^{A}$. Labour demand in research adds up with labour demand in final goods production to aggregate labour demand

$$
H_{t}=H_{t}^{A}+H_{t}^{Y}
$$

2.7. Market Clearing and Equilibrium Dynamics. In equilibrium, wages in goods production and R\&D equalize such that $\delta p_{t}^{A}=(1-\alpha) Y_{t} / H_{t}^{Y}$. By inserting demand (7) into the goods price $p_{t}=r_{t} / \alpha$ and the result into profits, the free entry condition can be written as $p_{t}^{A}=\pi_{t}=\alpha(1-\alpha) Y_{t} / A_{t}$. Next, use these two equations for $p_{t}^{A}$ to eliminate the price of blueprints and to arrive at labour demand $H_{t}^{Y}=A /(\alpha \delta)$ and thus $H_{t}^{A}=H_{t}-A /(\alpha \delta)$.

Inserting employment of researchers $H_{t}^{A}$ from (10), the definition of R\&D productivity $\delta$, and the definition of aggregate human capital into research output (9) provides the evolution of TFP as a function of current TFP $A_{t}$, human capital per person $h_{t}$, and size of the workforce $L_{t}$,

$$
A_{t+1}=\bar{\delta} A_{t}^{\phi} h_{t} L_{t}^{1-\nu}-\frac{1-\alpha}{\alpha} A_{t}
$$

which constitutes the human-capital augmented Romer-Jones result. 
The size of workforce grows at the fertility rate,

$$
L_{t+1}=n_{t} L_{t}
$$

For a given set of parameters fertility stays constant according to (3) implying that the number of children $\left(n_{t} L_{t}\right)$ and of old people $\left(L_{t} / n\right)$ evolves "in sync" with the workforce $L_{t}$.

For convenience physical capital is assumed to fully depreciate between periods $t$ and $t+1$ such that next period's capital stock consists of this period's savings. Inserting into $K_{t+1}=s_{t} L_{t}$ the solution for savings (1) and wages from (6) and (8) and substituting $H_{t}^{Y}=A /(\alpha \delta)$ provides evolution of aggregate capital as

$$
K_{t+1}=B K_{t}^{\alpha} A_{t}^{1-\alpha-\alpha(1-\phi)} h_{t} L_{t}
$$

with $B \equiv \beta(1-\alpha)(\alpha \bar{\delta})^{\alpha} /(1+\beta+\eta)$. The evolution of the economy is fully described by the four-dimensional system (4) and (11)-(13).

\section{Analysis: Balanced Growth}

\subsection{The Inverse Correlation between Productivity Growth and Population Growth.}

Let, in line with the literature, a balanced growth path be defined as a state of the economy at which growth rates do not change. For any variable $z$, the growth rate is denoted by $g_{z, t}=$ $\left(z_{t+1}-z_{t}\right) / z_{t}$ and its rate of change by $\hat{g}_{z, t} \equiv\left(g_{z_{t+1}}-g_{z_{t}}\right) / g_{z_{t}}$. Balanced growth thus requires

$\hat{g}_{z}=0$ for $z=A, K, h, L$. Given the simple structure of the model, these conditions are always fulfilled for human capital and the workforce. For $\hat{g}_{A}=0$ we obtain from (11) that along the balanced growth path

$$
\left(\frac{A_{t+1}}{A_{t}}\right)^{1-\phi}=\left(\frac{h_{t+1}}{h_{t}}\right)\left(\frac{L_{t+1}}{L_{t}}\right)^{1-\nu}=\left(\frac{h_{t+1}}{h_{t}}\right) n_{t}^{1-\nu} .
$$

Superficial inspection thus seemingly suggests that TFP growth and population growth are positively correlated. This is the macro-view of the economy, which disregards interaction on the micro-level and seemingly predicts - in line with the available R\&D-based growth literature - that higher population growth leads to higher productivity growth.

From micro-foundation, however, we have derived that both human capital and fertility are endogenous and via the quantity-quality trade-off inversely correlated. Inserting $n_{t}$ and $h_{t+1}$ 
from (3) and (4) provides the expression

$$
\left(\frac{A_{t+1}}{A_{t}}\right)^{1-\phi}=A_{E} \frac{\gamma \tau}{\eta-\gamma}\left(\frac{\eta-\gamma}{(1+\beta+\eta) \tau}\right)^{1-\nu} .
$$

For further analysis note that the most positive role that population growth could possibly play exists when there is no congestion in research, i.e. for $\nu=0$. In this case the expression simplifies further and the balanced growth rate of TFP and - after inserting (3) into (12) - the population growth rate are obtained as

$$
\begin{aligned}
g_{A} & =\left(\frac{\gamma A_{E}}{1+\beta+\eta}\right)^{1 /(1-\phi)}-1 \\
g_{L} & =\frac{\eta-\gamma}{(1+\beta+\eta) \tau}-1 .
\end{aligned}
$$

Inspecting the growth rates shows that a preference shock in terms of increasing weight of child quality in utility, $\gamma$, causes $g_{A}$ to rise and $g_{L}$ to fall. The opposite holds true for a decreasing weight of child quantity in utility. A proposition summarizes the main result of the paper.

Proposition 1. A change of preferences resulting in a child quantity-quality substitution leads on the aggregate to increasing TFP growth and decreasing population growth, i.e. it supports a negative correlation between TFP growth and population growth.

Note that congestion in research $(\nu>0)$ amplifies the effect by reducing the role of $n_{t}$ in TFP growth. More importantly, note that the result is independent from the size of $n_{t}$. In particular, it holds also when population growth $g_{L}=n_{t}-1$ is negative. Declining population is good for TFP growth.

For an intuition of the result recall the definition of aggregate human capital $H_{t}=h_{t} L_{t}$. Without congestion a positive effect of declining population on productivity requires that the change of child quality exceeds the change of child quantity such that $h_{t}$ grows more than $L_{t}$ falls. This is exactly what our model-parents provide. Obtain from (3) and (4)

$$
\frac{H_{t+1}}{H_{t}}=n_{t} \cdot\left(\frac{h_{t+1}}{h_{t}}\right)=\frac{\eta-\gamma}{(1+\beta+\eta) \tau} \cdot \frac{\gamma \tau A_{E}}{\eta-\gamma}=\frac{\gamma A_{E}}{1+\beta+\eta} \quad \Rightarrow \quad \frac{\partial\left(H_{t+1} / H_{t}\right)}{\partial \gamma}=\frac{A_{E}}{1+\beta+\eta}>0 .
$$

Note that the mechanism behind the result originates from the budget constraint and not from the utility function. We can thus be confident that it will hold for more general forms of utility as well. The crucial element in the budget constraint is the time costs of children $\tau$. To see this clearly consider a unit increase of $e_{t}$ in company with a unit reduction of $n_{t}$ such 
that total voluntary child expenditure $n_{t} e_{t}$ remains constant. This one-to-one quantity-quality substitution is not neutral. It sets free income $\tau w_{t} h_{t}$ because less time is needed for child rearing so that more time can be supplied on the labour market. The additionally earned income can be spend on current and future consumption and on further child expenditure $e_{t}$ implying that the negative effect from reduction of fertility is smaller than the positive effect on human capital such that $H_{t}=h_{t} n_{t}$ rises.

The intuition for a change of $\eta$ is obtained analogously. An interesting side-effect of a decrease of $\eta$ is that it - according to (1) - implies also a higher savings rate. Decreasing $\eta$ can thus explain the empirical regularity of a positive association of productivity growth and the savings rate (see Bernanke and Gürkaynak, 2001).

Interestingly, equation (15) predicts that a change of time costs for children $(\tau)$ affects population growth but not productivity growth. The intuition can be developed as above. Rising costs of children lead to lower fertility and higher voluntary expenditure per child. Obviously the negative effect on aggregate human capital $H_{t}=h_{t} L_{t}$ through lower fertility and the positive effect via higher human capital growth per capita are exactly levelling each other such that $H_{t+1} / H_{t}=\gamma A_{E} /(1+\beta+\eta)$ independently from $\tau$ and thus $\partial\left(H_{t+1} / H_{t}\right) / \partial \tau=0$.

The mechanics behind the result originate again from the budget constraint, but this time log-utility and its feature of balancing income and substitution effects plays a role as well. Higher child costs lead to lower child demand $n_{t}$ and lower available income $\left(1-\tau n_{t}\right) w_{t} h_{t}$. With unchanged preferences income and substitution effect are balancing each other such that total expenditure $n_{t} e_{t}$ remains constant. A utility function supporting a higher substitution effect would imply an overcompensating effect of human capital over fertility.

With respect to productivity growth, however, complicating the utility function is not required in order to obtain over-compensation of the fertility effect. If there is congestion in R\&D, i.e. if $\nu>0$ in $g_{A}=n_{t}^{1-\nu}\left(h_{t+1} / h_{t}\right)$, then the positive effect through rising human capital dominates the negative effect through falling fertility, an observation, which proves the following proposition.

PROPOSITION 2. If there is congestion in RED (stepping on toes) then increasing time costs for rearing children lead to lower population growth and higher TFP growth and thus a negative correlation between TFP growth and population growth.

3.2. Income Growth and Population Growth. In order to examine the rest of the model, we evaluate (13) along the balanced growth path (i.e. for $\left.\hat{g}_{K}=0\right)$ and substitute $\left(h_{t+1} / h_{t}\right)$ from 
(14). This provides

$$
\left(\frac{K_{t+1}}{K_{t}}\right)=\left(\frac{A_{t+1}}{A_{t}}\right)^{2-\phi}\left(\frac{L_{t+1}}{L_{t}}\right)^{\nu}
$$

Without congestion in $\mathrm{R} \& \mathrm{D}(\nu=0)$ the model predicts that growth of physical capital along the balanced growth path correlates positively with TFP growth but not with population growth. For $\phi \rightarrow 1$ the model predicts that the capital stock grows at the rate of TFP growth. Note the difference to neoclassical growth theory, which predicts that the capital stock grows at the rate of TFP growth plus the rate of population growth. With human capital and R\&D being endogenous, a positive association between capital growth and population growth emerges "only" when there is congestion in research.

Finally, substitute labour demand $H_{t}^{Y}=A_{t} /(\alpha \delta)$ into production (8) and take time-differences to get output growth $g_{Y_{t}}=\left(1+g_{K_{t}}\right)^{\alpha}\left(1+g_{A_{t}}\right)^{(1-\alpha)(2-\phi)}\left(1+g_{L t}\right)^{\nu(1-\alpha)}-1$. Insert this information into growth of output per worker $y_{t}=Y_{t} / L_{t}$, i.e. into $\left(1+g_{y_{t}}\right)=\left(1+g_{Y_{t}}\right) /\left(1+g_{L t}\right)$. In order to evaluate income per capita growth along the balanced growth path insert $g_{A}$ and $g_{K}$ from (14) and (16) to arrive at

$$
1+g_{y}=\left(\frac{h_{t+1}}{h_{t}}\right)^{\frac{2-\phi}{1-\phi}} n_{t}^{\frac{1-\nu}{1-\phi}} \quad \Rightarrow \quad \text { for } \nu=0: \quad 1+g_{y}=\left(\frac{h_{t+1}}{h_{t}}\right)^{\frac{2-\phi}{1-\phi}} n_{t}^{\frac{1}{1-\phi}} .
$$

Without congestion in $\mathrm{R} \& \mathrm{D}(\nu=0)$, superficial inspection suggests again a seemingly positive association between income growth $g_{y}$ and population growth (fertility).

However, with contrast to conventional R\&D-based growth theory, the result is reconciled with the empirical facts by inserting $n_{t}$ and $h_{t+1}$ from (3) and (4), providing for the case without congestion

$$
1+g_{y}=\left(\frac{\gamma \tau A_{e}}{\eta-\gamma}\right)^{\frac{2-\phi}{1-\phi}} \cdot\left(\frac{\eta-\gamma}{(1+\beta+\eta) \tau}\right)^{\frac{1}{1-\phi}} .
$$

Taking the derivatives with respect to $\gamma$ and $\eta$ provides a result analogously to Proposition 1 .

Proposition 3. A change of preferences resulting in a child quantity-quality substitution leads on the aggregate to increasing income per capita growth and decreasing population growth.

Furthermore, since $2-\phi>1$ :

Proposition 4. An increase of child-rearing costs leads on the aggregate to increasing income per capita growth and decreasing population growth. 
In contrast to productivity growth, congestion is not required for the result that a one-to-one child quantity-quality substitution has an impact on income growth. Since aggregate capital grows independently from population proportionally to productivity growth, the only effect of population growth originates through the "neoclassical" capital dilution effect. More people imply lower shares of capital and income per person. If there is congestion in $\operatorname{R} \& \mathrm{D}(\nu>0)$ the negative impact of population growth on income growth is further amplified through its dampening effect on productivity growth.

We can compare R\&D effort along the steady-state with the earlier R\&D-based growth models. Models of the first generation (Romer, 1990; Aghion and Howitt, 1992) predict constant TFP growth for constant number of researchers. For this to be true the knife-edge assumption $\phi=1$ has to hold. Models of the second generation (Jones, 1995, Segerstrom, 1998) predict based on $\phi<1$ that constant TFP growth is realized for a constant population share of researchers and positive population growth, implying that constant economic growth requires a perpetually rising number of people employed in $R \& D$ and perpetually rising $R \& D$ expenditure. Ha and Howitt (2007) have argued that empirical evidence for the U.S. growth experience after 1950 supports models of the first generation. Models of the first generation, however, have the unpleasant features of being based on the knife-edge assumption $\phi=1$ and of relying on a constant population. The present theory reconciles the earlier theories. It abandons the knifeedge assumption but preserves the empirical relevant associations between research effort and TFP.

Proposition 5. At the steady-state constant TFP growth is associated with a constant share of the population working in RED and constant RED expenditure share of GDP. These results hold true for $\phi<1$ irrespective of whether the number of people employed in RED is rising, constant, or declining. If the population stays constant, constant TFP growth implies a constant number of workers engaged in RED.

For a proof let the number of workers in goods production be denoted by $L_{t}^{Y}$. Begin with noting that the share of workers in goods production is given by $L_{t}^{Y} / L_{t}=\left(h_{t} L_{t}^{Y}\right)\left(h_{t} L_{t}\right) /=H_{t}^{Y} / H_{t}$. Insert $H_{t}^{Y}=A_{t} /\left(\alpha \delta H_{t}\right)$ and the definitions of $H_{t}$ and $\delta$ to get $L_{t}^{Y} / L_{t}=A_{t}^{1-\phi} /\left(\alpha \bar{\delta} h_{t} L_{t}^{1-\nu}\right)$. Conclude from (14) that numerator and denominator of this expression are growing at equal rates at the steady-state. Thus $L_{t}^{Y} / L_{t}$ stays constant implying a constant population share in R\&D. 
For the second part of the proof, $\mathrm{R} \& \mathrm{D}$ expenditure is given by $R_{t}=w_{t} H_{t}^{A}$ and its share of GDP by $R_{t} / Y_{t}=w_{t} H_{t}^{A} / Y_{t}$. Insert wages from (6) to get $R_{t} / Y_{t}=(1-\alpha) H_{t}^{A} / H_{t}^{Y}$, which is constant since $H_{t}^{Y} / H_{t}$ and $H_{t}^{A} / H_{t}$ are constant along the steady-state.

3.3. Pre-Modern Times. The present theory proposes a theory of R\&D-driven technological progress which predicts a negative association of TFP growth and population growth, a result that is not rejected by cross-country data for the second half of the 20th century. For most part of human history, however, Kremer (1993) has impressively documented a positive association between population growth and TFP growth. Strictly speaking, the present model is indeed inappropriate to analyse pre-modern growth. In pre-modern times market R\&D contributes little to productivity growth (Mokyr, 2001) and a Malthusian mechanism is operative preventing that TFP growth translates into income per capita growth (Galor, 2005).

Overstretching the theory a bit to make a statement about pre-modern times is nevertheless useful for an assessment of conventional R\&D-based growth. For that purpose suppose that education assumes the the corner solution. Parental preference for education $(\gamma)$ is too low or productivity of the schooling system $\left(A_{E}\right)$ is too low such that (4) implies $h_{t+1}=$ $\max \left\{A_{E} \gamma \tau /(\eta-\gamma) h_{t}, 1\right\}=1$ and therefore for all $t>1$ that $\left(h_{t+1} / h_{t}\right)=1$. A constant level of human capital per capita is probably a good first approximation for most of the history considered by Kremer. Inserting this information into (14) we get productivity growth

$$
g_{A}=n_{t}^{\frac{1-\nu}{1-\phi}}-1
$$

The obvious - and this time indeed correct - conclusion is that there is a unique positive association between productivity growth and population growth. This special case is the overlapping generations version of the standard R\&D-based growth model (Jones, 1995).

\section{Growth in Modern vs. Post-Modern Societies}

Summarizing we can distinguish three stages or eras of economic growth.

(1) Pre-modern growth as the era during which economic growth is driven solely by population growth (conventional second generation R\&D-based growth theory, the corner solution of the present model).

(2) Modern growth as the era during which population growth is low and R\&D-based economic growth is driven by both increasing number of researchers and increasing human 
capital per person (conventional R\&D-based growth theory with human accumulation, the interior solution of the present model when $n>1$ ).

(3) Post-modern growth as the era during which the population is declining and R\&D-based economic growth is fuelled solely by human capital growth (the present model when the interior solution holds with $n<1$.

Since Proposition 4 and 5 hold irrespective of the size of $n$ we can conclude

COROllary 1. Growth of income per capita is - ceteris paribus - higher for the post-modern society than for the modern society.

The explanation remains the same as developed with Proposition 1. A change of preferences that leads to a child quantity-quality substitution frees extra parental time that is used to earn extra income of which a part is invested in education. As a consequence the positive impact of education exceeds the negative impact of population size such that aggregate human capital $H=h \cdot L$ and $\mathrm{TFP}$ are growing at higher rates than before. If there is congestion in $\mathrm{R} \& \mathrm{D}$ a second positive effect shows up because there is less stepping-on-toes.

TABle 3: 2 Societies

\begin{tabular}{lll}
\hline \hline & Modern & Post-Modern \\
\hline & $\eta=1.8$ & $\eta=1.6$ \\
$2 n$ & 2.22 & 1.76 \\
$g_{L}$ & 0.53 & -0.62 \\
$g_{h}$ & 0.59 & 2.05 \\
$g_{H}$ & 1.12 & 1.41 \\
$g_{A}$ & 1.61 & 2.02 \\
$g_{Y}$ & 2.75 & 3.46 \\
$g_{y}$ & 2.21 & 4.11 \\
\hline
\end{tabular}

Parameters for both: $\alpha=0.4, \beta=0.8$ (implied savings rate $s=0.22$ and $s=0.24), \gamma=1, A_{E}=4.5, \delta=1, \phi=0.3, \nu=0$. Annual growth rates along the balanced growth path in percent. Conversion from generational to annual rates assumes a length of a generation of 20 years.

Table 3 illustrates the result with a numerical example. Generational growth rates are converted to annual ones in order to better convey the result that the model produces growth rates in empirically plausible magnitudes. We assume a capital share of 0.4 , an investment rate of 0.22, and that in a Modern Society, a couple has 2.2 children, i.e. fertility is slightly above replacement level. The implied preference parameters are $\beta=0.8, \gamma=1$ and $\eta=1.8$ and the 
implied population growth rate is 0.53 percent. Setting $A_{E}=4.5$ provides growth of human capital per capita at rate 0.59 , i.e. growth of quantity and quality contribute about the same to aggregate human capital growth. Setting $\delta=1, \phi=0.3$ and $\nu=0$ predicts a TFP growth rate of 1.6 percent, a growth rate of aggregate GDP of 2.7 percent and a growth rate of income per capita of 2.2 percent.

The Post-modern Society shares all parameters with the Modern Society aside from a shift of preferences. The weight for children $\eta$ is 1.6 (instead of 1.8). The induced child quantity-quality substitution implies that a post-modern couple has 1.76 children, which is about the average value observed across the G-8 countries in 2005 . The population shrinks now at an annual rate 0.6 percent. However, as explained above, individual human capital growth overcompensates the quantity effect. It grows at a rate of 2 percent such that aggregate human capital and TFP grow at a higher rate than before (at 1.4 and 2 percent). Consequently aggregate GDP and income per capita grow at higher rate than before. For income per capita the model predicts almost a doubling of steady-state growth.

We can use the example to illustrate adjustment dynamics. Figure 1 shows the transition from a modern society to a post-modern one by assuming that the modern society rests at the steady-state of Table 3 and that at time 20 (i.e. after one generation) a preference change of $\eta$ from 1.8 to 1.6 occurs. While population and human capital adjust monotonously, there are damped cycles of TFP growth and of income per capita growth (due to the non-linear nature of $R \& D$ production (11). As a consequence, focussing the observation on a wrong time-window (e.g. between year 40 and 60) could misleadingly provoke the conclusion that income growth and TFP growth are declining for the post modern society. Comparing larger time-windows (and in the limit steady-states) avoids this fallacy and produces the conclusion of higher growth for the post-modern society in the long-run.

\section{Conclusion}

In this paper we have integrated into an R\&D-based growth model an endogenous, microfounded evolution of population growth and human capital accumulation and have shown how this modifies some conclusions from earlier R\&D-driven growth theory. While earlier models (in the spirit of Romer 1990 or Jones 1995) predicted that population growth is positively associated with economic growth, or even - in the Jones case - essential for having economic growth 
Figure 2: Adjustment Dynamics: Postmodern Society
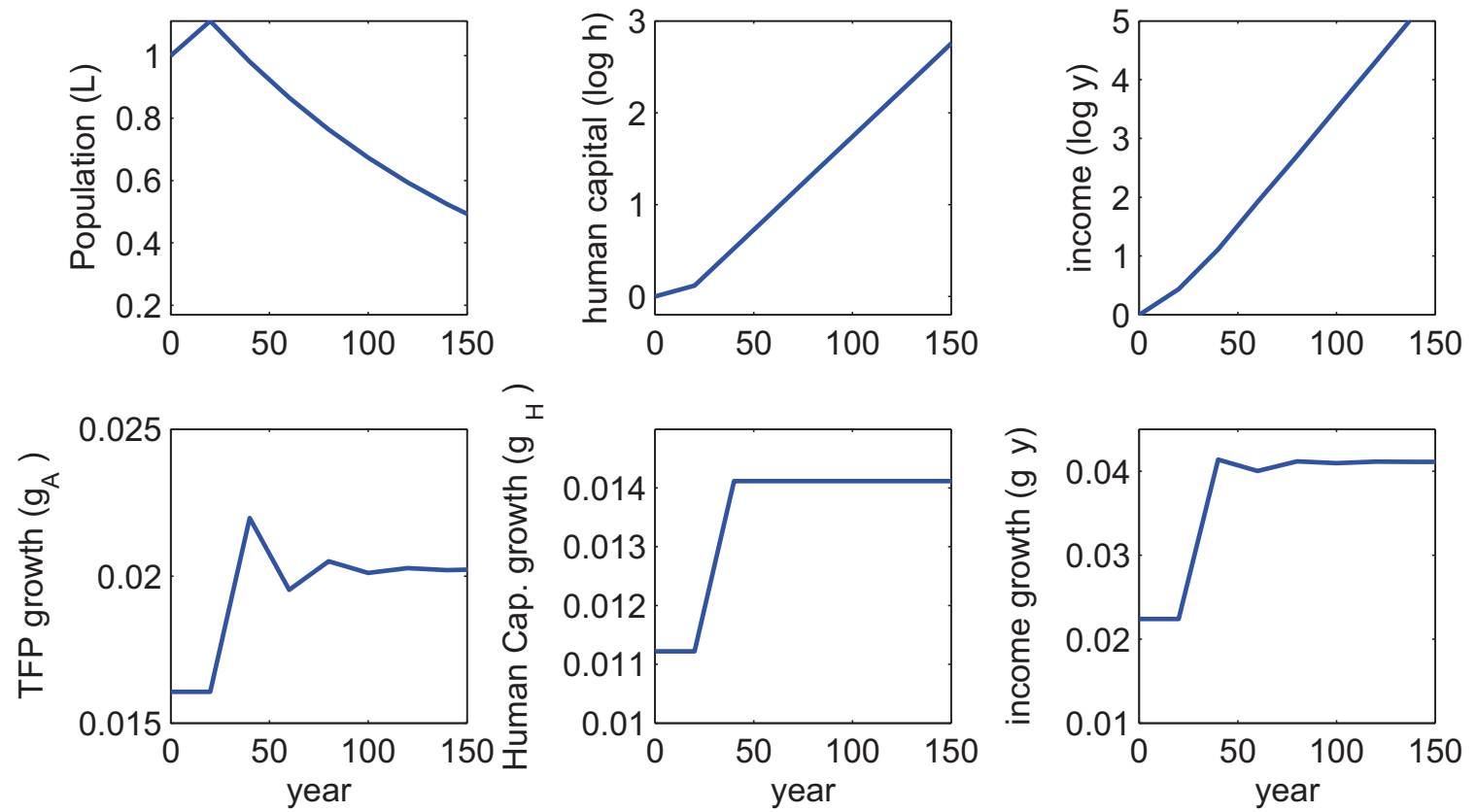

Parameters from Table 3. Initially: modern society. In year 20 (after one generation): $\eta=1.6$. Convergence towards Post-modern society from Table 3).

at all, our micro-founded theory predicts that population growth is negatively associated with productivity growth and income growth. It is therewith harder to falsify by the available data for the 20th century.

Since we have maintained all central elements from the firms' side of R\&D-based growth theory it is clear that the new result originates from the households' side. The basic mechanism is generated by the interaction of child quality and quantity in the households' budget constraint independently from the specification of preferences so that we are confident that our result will be robust against a sophistication of the households' utility function.

Specifically, a substitution of child quantity $n$ by child quality (i.e. expenditure on education) $e$ that keeps total child expenditure $e \cdot n$ constant sets free parental time, which can be used to earn extra income. Parts of the additional income is spend on children such that overall child expenditure rises more strongly than child quantity falls. At the macro side of the economy this trade-off means that human capital per person $h$ increases more strongly than the number of persons $L$ falls such that total available human capital $h \cdot L$ increases. Given that human capital is the driving force in $R \& D$ this entails higher $R \& D$ output and higher $R \& D$-based growth.

Of course our proposed growth motor can be easily choked off by assuming a more pessimistic function for education. The crucial assumption for perpetual growth is not that there are no 
decreasing returns to education expenditure. In equilibrium the expenditure share of education is constant (the OLG equivalent of a constant share of life-time spent on education in the nonoverlapping generations, Mincer-type approach to education). Indeed the model can be easily generalized towards decreasing returns. The crucial assumption for perpetual growth is the linear intergenerational transmission of human capital, i.e. the assumption that the current generation is capable to transport its knowledge times a multiplier larger than one to the next generation. While it is impossible to say whether such a process of knowledge transmission can be sustained forever, it is in any case easier conceivable than a perpetually growing population. Human capital is a metaphysical entity measured in value-units (compare, for example, the value of knowledge acquired by a university study of medical science now and 100 years ago) whereas population is a physical entity bounded by physical constraints (for example, space on earth).

Instead of venturing forth into the domain of speculation about the distant future of humanity we would like to emphasize that our model is a metaphor to explain economic growth in the recent past (say the last century), the present, and the near future (say within the limit of the time horizon of the UN population projections). It is not a theory for economic growth in the very distant future. In the recent past, we observed high TFP growth in line with high growth of human capital and low and increasingly negative population growth, and we expect these trends to continue for a while. In this respect the main message delivered by the model is an optimistic one: the fact that fertility is below replacement level and population is declining is less threatening than suggested by conventional R\&D-based growth theory. On the contrary, taking child quantity-quality substitution into account, fertility below replacement could be an early indicator for high future productivity growth.

In the very long-run it is likely that the UN predictions of fertility below replacement and negative population growth run against physical and economic limits. If population density becomes too thin we would expect indivisibilities to occur and technologies to become increasingly resistant against quantity-quality substitution (for example, it could take at least one person to steer a vehicle, to run a firm, or - within the context of the model - to invent a new design for an intermediate good). We would then expect that markets and/or policy reacts by generating a lower relative price of children and/or a higher relative price of raw labour in production. With ongoing adjustment of prices we would probably expect indeed convergence towards a stable population in the very long-run. 
Here we have treated the preference change that triggered the transition towards the postmodern society as exogenous in order to focus on the power of the child-quantity quality tradeoff in R\&D-based growth. The model would of course gain more realism if the transition were generated endogenously in the spirit of unified growth theory. An interesting framework for integrating the post-modern era into unified growth theory is provided by Strulik and Weisdorf (2008). They show how in a two-sector economy steeply increasing TFP in manufacturing and the associated decrease of prices for manufactured goods in the 20th century explain declining fertility below replacement (i.e. a post-modern era of increasing consumerism) and how market forces restore fertility at replacement level in the very long-run. Combining their demo-economic theory with the quantity-quality theory of R\&D-based growth is a challenging task for the future. 


\section{References}

Aghion, P. and P. Howitt, 1992, A model of growth through creative destruction, Econometrica 60, 323-702.

Aghion, P. and P. Howitt, 2009, The Economics of Growth, MIT Press, Cambridge, MA.

Ahituv, A., 2001, Be fruitful or multiply: On the interplay between fertility and economic development, Journal of Population Economics 14, 51-71.

Andreoni, J., 1989, Giving with impure altruism: Applications to charity and Ricardian equivalence, Journal of Political Economy 97, 1447-1458.

Barro, R.J., 2001, Human capital and growth, American Economic Review 91, 12-17.

Becker, G.S., 1960, An economic analysis of fertility, in: National Bureau of Economic Research (ed), Demographic and Economic Change in Developed Countries, Princeton University Press, Princeton, 209-231.

Bernanke, B.S. and Gürkaynak, R.S., 2001, Is growth exogenous? Taking Mankiw, Romer, and Weil seriously, NBER macroeconomics annual 16, 11-57.

Bongaarts, J., 2001, Fertility and reproductive preferences in post-transitional societies, Population and Development Review 27, 260-281.

Bongaarts, J., 1999, Fertility decline in the developed world: Where will it end?, American Economic Review 89, 256-260.

Bottazi, L. and G. Peri, 2003, Innovation, demand, and knowledge spillovers: Evidence form European patent data, European Economic Review 47, 687-710.

Brander, J.A., and S. Dowrick, 1994, The Role of Fertility and Population in Economic Growth, Journal of Population Economics 7, 1-25.

Caldwell, J.C. and Schindlmayr, T., 2003, Explanations of the fertility crisis in modern societies: A search for commonalities, Population Studies 57, 241-263.

Ciccone, A. and Papaioannou, E., 2009, Human capital, the structure of production, and growth, The Review of Economics and Statistics 91, 66-82.

Comin, D., Easterly, W., and Gong, E., 2010, Was the wealth of nations determined in 1000 BC?, American Economic Journal: Macroeconomics 2, 65-97.

Connolly, M. and Peretto, P.F., 2003, Industry and the family: two engines of growth, Journal of Economic Growth 8, 115-148.

Dalgaard, C.-J. and Kreiner, C.T.,, 2001, Is declining productivity inevitable?, Journal of Economic Growth 6, 187-203.

Dalgaard, C.-J. and Jensen, M.K., 2009, Life cycle savings, bequest and a diminishing impact of scale on growth, Journal of Economic Dynamics and Control 33, 1639-47. 
Dinopoulos, E. and P. Thompson, 1998, Schumpeterian growth without scale effects, Journal of Economic Growth 3, 313-335.

Funke, M. Strulik, H., 2000, On endogenous growth with physical capital, human capital, and product variety', European Economic Review 44, 491-515.

Galor, O., 2005, From stagnation to growth: unified growth theory, in: P. Aghion and S. Durlauf, Handbook of Economic Growth Vol 1A, Elsevier, Amsterdam.

Galor, O., 2010, Comparative economic development: insights from unified growth theory, International Economic Review, forthcoming.

Goldstein, J. and Lutz, W. and Testa, M.R., 2003, The emergence of sub-replacement family size ideals in Europe, Population Research and Policy Review 22, 479-496

Grossmann, V., 2010, Entrepreneurial innovation and economic growth, Journal of Macroeconomics, forthcoming.

Growiec, J., 2006, Fertility choice and semi-endogenous growth: where Becker meets Jones, Topics in Macroeconomics 6, Article 10.

Ha, J. and P. Howitt, 2006, Accounting for trends in productivity and R\&D, Journal of Money, Credit, and Banking 39, 733-774.

Hanushek, E.A., 1992, The trade-off between child quantity and quality, Journal of Political Economy 100, 84-117.

Herzer, D., Vollmer, S., and Strulik, H., 2010, The long-run determinants of fertility: One century of demographic change 1900-1999, Discussion Paper, University of Hannover.

Howitt, P. 1999, Steady endogenous growth with population and R\&D inputs growing, Journal of Political Economy 107, 715-30.

Jaffe, A. M. Tratjenberg, and R. Henderson, 1993, Geographic localization of knowledge spillovers as evidenced by patent citations Quarterly Journal of Economics 63, 577-598.

Jones, C.I., 1995, R\&D-based models of economic growth, Journal of Political Economy 103, 759-784.

Jones, C.I., 1999, Growth: with or without scale effects? ,American Economic Review Papers and Proceedings 89, 139-44.

Jones, C.I., 2001, Was an industrial revolution inevitable? Economic growth over the very long run, Advances in Macroeconomics 1, 1-43.

Kelley, A.C. and Schmidt, R., 1995, Aggregate population and economic growth correlations: The role of the components of demographic change", Demography 32, 543-55.

Keller, W., 2002, Geographic localization of international technology diffusion, American Economic Review 92, 120-142.

Kortum, S, 1997, Research, patenting, and technological change, Econometrica 65, 1389-1419. 
Kremer, M., 1993, Population growth and technological change: one million B.C. to 1990, Quarterly Journal of Economics 108, 681-716.

Krueger, A.B. and Lindahl, M., 2001, Education for growth: why and for whom?, Journal of Economic Literature, 39, 1101-1136.

Li, C.-W., Endogenous vs. semi-endogenous growth in a two R\&D-sector model", Economic Journal, C109-C122.

Lucas, R. E., 1988, On the mechanics of economic development, Journal of Monetary Economics $22,3-42$.

Mankiw, G., D. Romer and D. Weil, 1992, A contribution to the empirics of economic growth. Quarterly Journal of Economics 107,407-37.

Peretto, P.F., 1998, Technological change and population growth, Journal of Economic Growth 3, 283-311.

Preston, S.H. and Hartnett, C.S., 2008, The future of American fertility, NBER Working Paper 14498.

Romer, P.M., 1990, Endogenous technological change, Journal of Political Economy 98, S71S102.

Rosenzweig, M. 1990, Population growth and human capital investments: theory and evidence, Journal of Political Economy 98, S38-S70.

Rosenzweig, M., and K.I. Wolpin, 1980, Testing the quantity-quality fertility model: the use of twins as natural experiment, Econometrica 48, 227-240.

Segerstrom, P., 1998, Endogenous growth without scale effects, American Economic Review 88, 1290-1310.

Segerstrom, P., 2000, The Long-Run Growth Effects of R\&D Subsidies", Journal of Economic Growth 5, 277-305.

Strulik, H., 2005, The Role of Human Capital and Population Growth in R\&D-Based Models of Economic Growth, Review of International Economics 13, 129-145.

Strulik, H. and J. Weisdorf, 2008, Population, food, and knowledge: A simple unified growth model, Journal of Economic Growth 13, 169-194.

Strulik, H. and S. Vollmer, 2010, The fertility transition around the World 1950-2005, Working Paper, Harvard University.

UN, 2009, United Nations World Population Prospects: 2008 revision United Nations Department of Economic and Social Affairs, Population Division. New York.

U.S. National Center for Health Statistics. 2010, National Vital Statistics Reports Volume 58 (16), Births: Preliminary Data for 2008, U.S. Department of Health and Human Services. 
van de Kaa, D.J., 2001, Postmodern fertility preferences: From changing value orientation to new behavior, Population and Development Review 27, 290-331.

Weil, D., 2005, Economic Growth, accompanying data set, Pearson, Boston.

Young, A., 1998, Growth Without Scale Effects, Journal of Political Economy 106, 41-63. 


\section{VIENNA INSTITUTE OF DEMOGRAPHY}

\section{Working Papers}

Prettner, Klaus and Alexia Prskawetz, Demographic Change in Models of Endogenous Economic Growth. A Survey, VID Working Paper 08/2010.

Flandorfer, Priska, Christian Wegner, and Isabella Buber, Gender Roles and Smoking Behaviour, VID Working Paper 07/2010.

Barakat, Bilal, Johannes Holler, Klaus Prettner, and Julia Schuster, The Impact of the Economic Crisis on Labour and Education in Europe, VID Working Paper 06/2010.

Grafeneder-Weissteiner, Theresa and Klaus Prettner, Agglomeration Processes in Ageing Societies, VID Working Paper 05/2010.

Buber, Isabella, Parity-specific weights for the Austrian Generations and Gender Survey, VID Working Paper 04/2010.

Testa, Maria Rita, She wants, he wants: Couple's childbearing desires in Austria, VID Working Paper 03/2010.

Buber, Isabella, Wissenschaftlerinnen in Österreich - Zusatzerhebung im Rahmen des GGS.Dokumentation der Datenerhebung und deskriptive Ergebnisse, VID Working Paper 02/2010.

Kuhn, Michael, Stefan Wrzaczek, Alexia Prskawetz, and Gustav Feichtinger, Externalities in a Life-Cycle Model with Endogenous Survival, VID Working Paper $01 / 2010$.

Prettner, Klaus, Population Ageing and Endogenous Economic Growth, VID Working Paper 08/2009.

Št’astná, Anna and Tomáš Sobotka, Changing Parental Leave and Shifts in Second and Third-Birth Rates in Austria, VID Working Paper 07/2009.

Prettner, Klaus and Alexia Prskawetz, Decreasing Fertility, Economic Growth and the Intergenerational Wage Gap, VID Working Paper 06/2009.

Wegner, Christian and Marc Luy, Determinants of General Health and Specific Diseases of Elderly Women and Men: A Longitudinal Analysis for Western and Eastern Germany, VID Working Paper 05/2009.

The Vienna Institute of Demography Working Paper Series receives only limited review. Views or opinions expressed herein are entirely those of the authors. 